\title{
EFFECT OF THE POURING TEMPERATURE ON MICROSTRUCTURE AND TENSILE PROPERTIES OF A356 ALUMINUM ALLOY VIA SEMISOLID CASTING USING SLOPE COOLING PLATE.
}

\author{
Mabrouk, W. M. ${ }^{*}{ }^{\prime}$; Moussa, M. E. ${ }^{\dagger}$; Abdelwahab, S. A. ${ }^{*}$ and Ali, A. I. \\ * Department of Production Technology, Faculty of Industrial Education, Helwan University, \\ Saray El-Quba, 11281 Cairo, Egypt. \\ ${ }^{\dagger}$ Department of Manufacturing Technology, Laboratory of Foundry, Central Metallurgical \\ Research and Development Institute (CMRDI), P.O. Box 87, Helwan, Cairo, Egypt. \\ ${ }^{*}$ Basic Science Department, Faculty of Industrial Education, Helwan University, Saray El- \\ Quba, 11281 Cairo, Egypt. \\ $\S$ Corresponding author E-mail address: waleed181990@ gmail.com
}

\begin{abstract}
The cooling slope casting process has gained significant importance for the manufacturing of semisolid feedstock aluminum alloys, which find applications in the automotive and aerospace industries. The effect of the pouring temperatures on the microstructure of A356 aluminum alloy via semisolid casting using the slope cooling plate has been investigated. The prepared alloy that becomes semisolid at the end of the cooling slope plate is consequently poured into a sand mold. Without using the slope cooling plate, the $\alpha$-Al phases became coarse dendritic structure with an average length of about $287.5 \mu \mathrm{m}$. In case of using the slope cooling plate at the optimum pouring temperature of $640^{\circ} \mathrm{C}$, The $\alpha-\mathrm{Al}$ phase developed a fine globular structure with the average grain size of about $72.6 \mu \mathrm{m}$. The tensile properties of the investigated A356 alloy were improved by the application of semisolid casting at the optimum pouring temperature of $640^{\circ} \mathrm{C}$. The ultimate tensile strength and the elongation of the investigated alloy significantly increased from $102 \mathrm{MPa}$ and $1.175 \%$ without semisolid casting to $113 \mathrm{MPa}$ and $3.6 \%$ with semisolid casting at the optimum pouring temperature of $640^{\circ} \mathrm{C}$, respectively then gradually decreased with further increasing the pouring temperature. The fracture mechanism has been also investigated.
\end{abstract}

Keywords: A356 alloy, Semisolid casting, Slope cooling plate, Microstructure, Modification, Tensile properties.

\section{INTRODUCTION}

The semisolid casting of alloys is a very important aspect of the present-day manufacturing of applications; some examples of these applications are engine suspension mounts and steering knuckles for some automobile brands, aviation, and marine components. Semisolid metal (SSM) casting of a metallic alloy is carried out at a temperature between its equilibrium liquidus and solidus temperatures. The basic requirement of semisolid casting is the slurry with nearly spherical primary $\alpha$-Al particles [1-4]. Over the past decades, a substantial amount of work has been carried out in the field of semisolid metal processing (SSMP) for its unique capability to form nearnet shape products $[5,6]$. There are several key process parameters such as mold material, mold temperature, cooling slope length, cooling slope angle, superheat and pouring temperature, which directly influences the final microstructure of the solidified 
slurry during cooling slope processing [7]. The key element in the SSMP is the globular microstructure rather than dendritic microstructure and it is the thixotropic behavior of the semi-solid slurry, which reduces the porosity in the castings $[5,6]$.

Compared with conventional techniques, SSMP provides several advantages like lower forming temperature, higher production rate, higher product quality and improvement of the mechanical properties through microstructural refinement [2, 3, 8, and 9].

Aluminum alloys are amongst the most prominent materials used in the automotive industries. Among the aluminum alloys, the Al-Si alloys have exceptional casting characteristics and most of the parts are made from conventional casting alloys such as A356, A360 and A357 due to their combination of properties such as high fluidity, good castability, high specific strength and good resistance to corrosive attack which makes them advantageous for both small and intricate castings such as motor parts and miscellaneous fittings as well as comparatively large structural shapes. Nowadays, many vehicles use aluminum engine blocks instead of cast iron, so significant weight reduction is achieved. Aluminum castings are used in almost 100\% of pistons; about $75 \%$ of engine cylinder heads, $85 \%$ of intake manifolds, and $40 \%$ of chassis applications in automotive power trains [10-14].

The slope cooling plate process is used to transform microstructure from dendritic to globular shape by a detachment of nuclei. This process is a useful technique for preparing slurry due to its low cost and high efficiency [15]. Therefore, this work aims at investigating the effect of the pouring temperatures on the microstructure of A356 aluminum alloy via semisolid casting using the slope cooling plate.

\section{EXPERIMENTAL WORK}

\subsection{Materials and processing}

Commercial pure Al (99.99 wt.\% purity), Si (99.98 wt.\% purity) and Mg (99.96 wt.\% purity) were used as starting materials. Charges of about $20 \mathrm{~kg}$ with the nominal composition of A356 aluminum alloy were prepared as the base material in the present study. The charge was melted in a graphite crucible by a $200 \mathrm{~kW}$ medium frequency induction furnace. Before the melting process, charge calculations were performed and with respect to experience, the $90 \%$ efficiency of the melting process and $10 \%$ losses during melting can be estimated and be in consideration. Firstly, commercial Al ingots were melted to above $660^{\circ} \mathrm{C}$ and then silicon and magnesium were added into $\mathrm{Al}$ melt. After that, the melt was heated to above $750^{\circ} \mathrm{C}$, and kept about $30 \mathrm{~min}$ in order to get full homogenization. Finally, the melt was poured into a cast iron mold. The chemical compositions of the prepared alloy were measured with inductively coupled plasma optical emission spectroscopy (ICP-OES) (model Optima 2000, Germany), as shown in table 1.

Table (1): The chemical composition of the prepared A356 alloy (wt.\%).

\begin{tabular}{|c|c|c|c|c|c|}
\hline $\mathbf{A l}$ & $\mathbf{S i}$ & $\mathbf{M g}$ & $\mathbf{F e}$ & $\mathbf{C u}$ & $\mathbf{M n}$ \\
\hline 92.70 & 6.87 & 0.297 & 0.12 & 0.01 & 0.003 \\
\hline
\end{tabular}


The solidification characteristic of the prepared alloy was confirmed using thermal analysis in order to designate experimental conditions. The thermal analysis test sample was obtained by pouring the quantity of the melt at $750^{\circ} \mathrm{C}$, into standard Quik-Cup resin-bonded sand cup with dimensions described in figure 1 . A high sensitivity type $\mathrm{K}$ thermocouple (chromel-alumel) located horizontally at the center of the cup, facilitated the capturing of the temperature during solidification. The thermocouple within the mold was protected using a silica glass tube. The data for thermal analysis were collected using a data logger and transferred to a personal computer for analysis. Thermal analysis trial was repeated three times to ensure reproducibility of the results. From the thermal analysis data, the cooling curve with its first derivative curve was plotted as shown in figure 2 . The primary $\alpha(\mathrm{Al})$ began to precipitate from the prepared alloy melt at $624^{\circ} \mathrm{C}$, and the eutectic reaction occurred at about $569^{\circ} \mathrm{C}$.

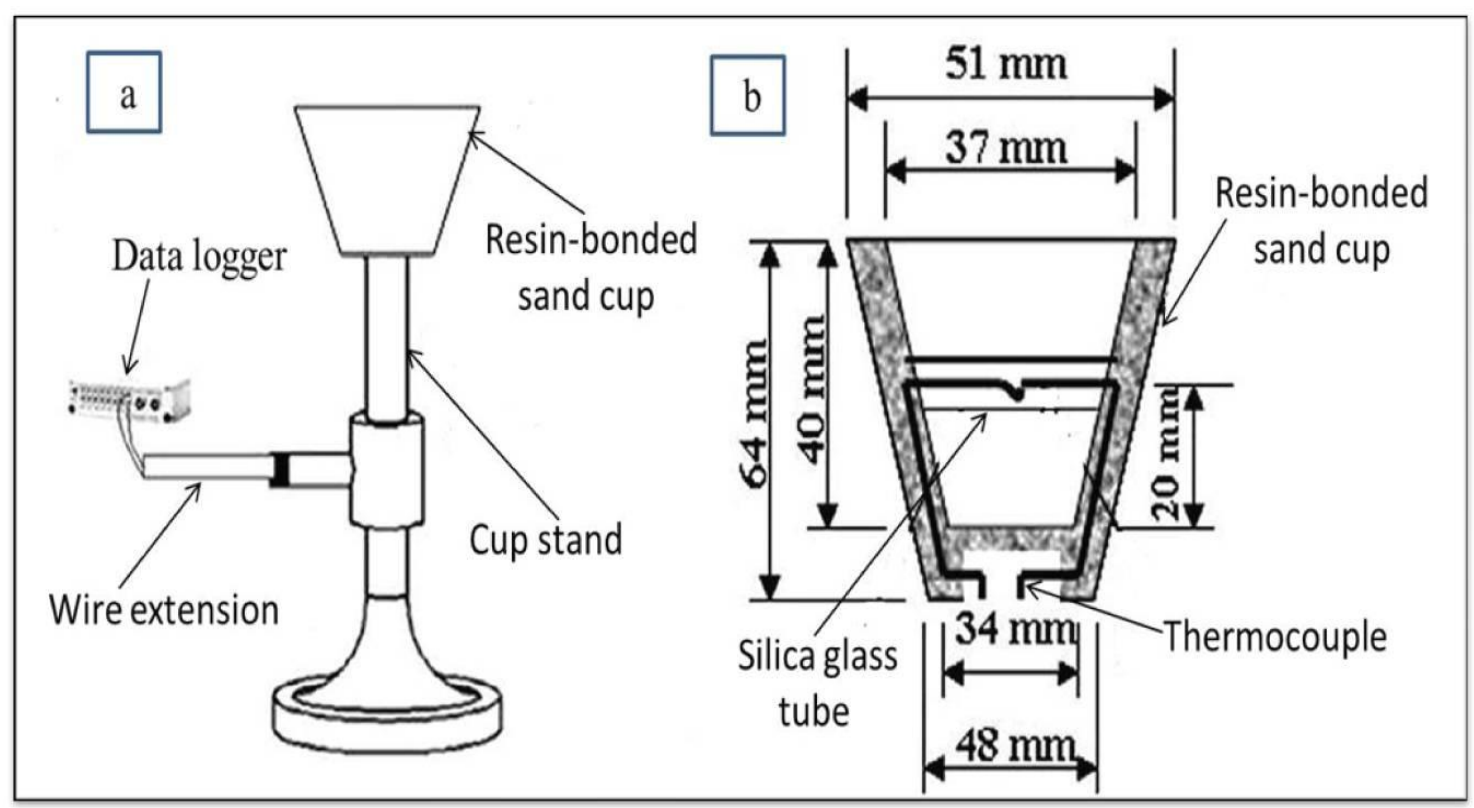

Fig. 1: Schematic of (a) experimental setup for thermal analysis and (b) resinbonded sand cup with type $K$ thermocouple.

After that, the investigated A356 aluminum alloy ingots were remelted for subsequent experiments. The semisolid casting using the slope cooling plate was studied at different designated pouring temperatures $\left(625,640,680,700^{\circ} \mathrm{C}\right)$ above the liquidus temperature of the investigated alloy of $624^{\circ} \mathrm{C}$, in order to result different melt conditions after hitting the cooling plate ranging from fully molten to semisolid states (figure 2). The resultant melt was poured onto the surface of a steel cooling slope (CS). After flowing through the slope, it is transferred into the sand mold with dimensions of outer diameter of $100 \mathrm{~mm}$, inner diameter of $40 \mathrm{~mm}$ and length of $250 \mathrm{~mm}$. The cooling plate was adjusted fixed at $30^{\circ}$ with respect to the horizontal plane and was cooled by water circulation underneath. The length of fixed at $500 \mathrm{~mm}$ was used. The melt becomes semisolid by the end of the cooling slop as shown in figure 3. For comparison, a sample without the application of semisolid was prepared. 


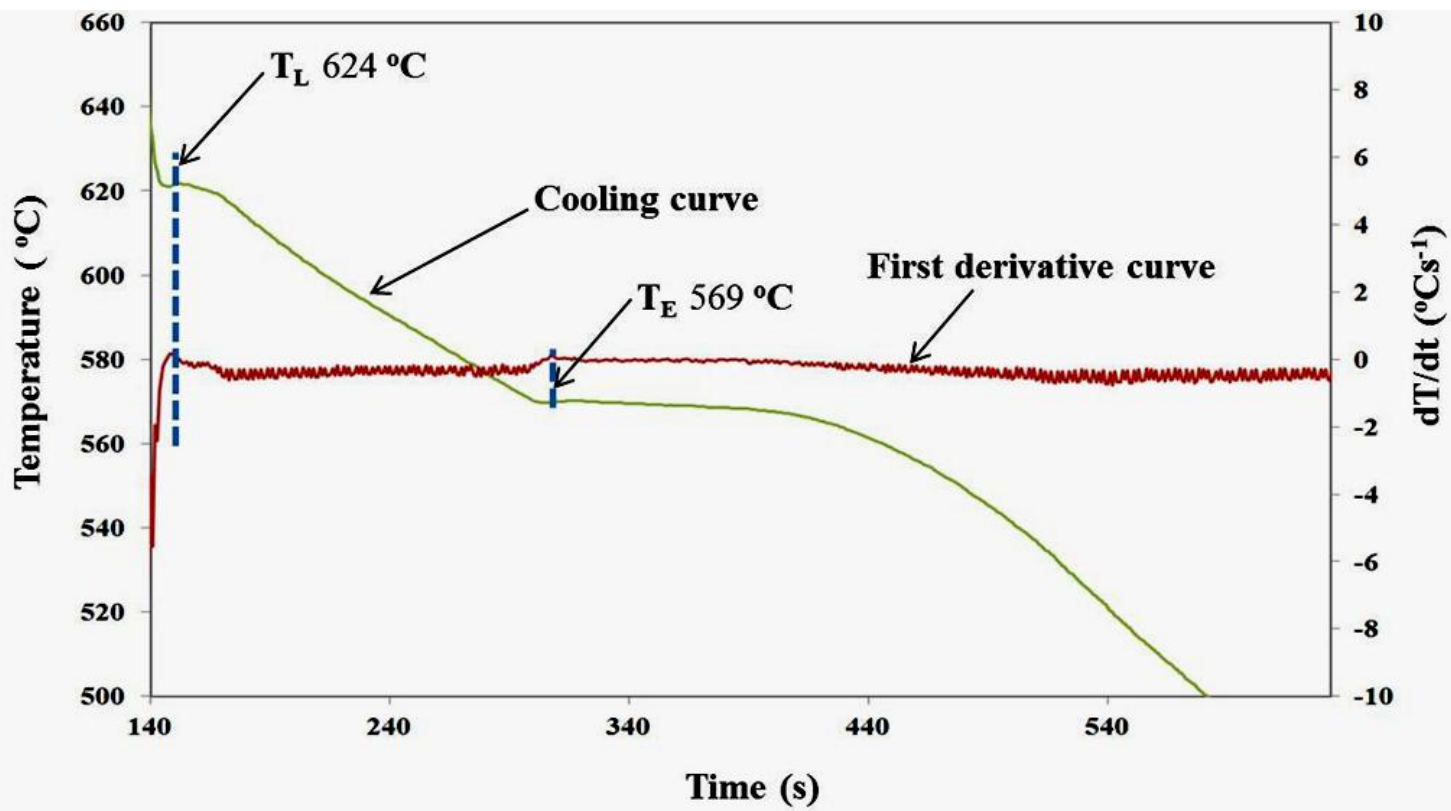

Fig. 2: The cooling curve with its first derivative curve of the prepared A356 aluminum alloy.

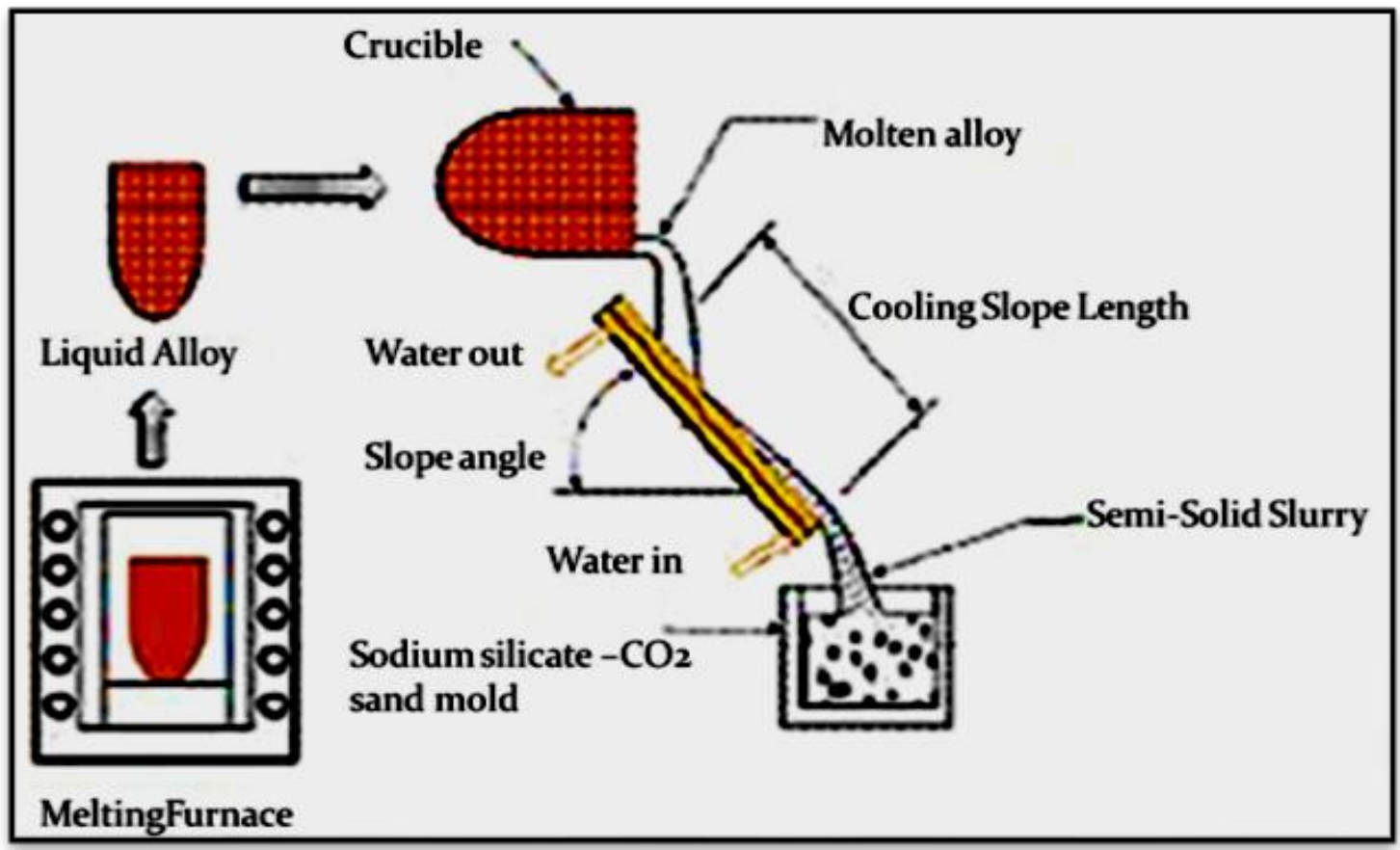

Fig. 3: Schematic illustration of the slope plate casting process.

\subsection{Materials Characterization}

All metallographic specimens were cut from the bottom of the castings at the same position of $10 \mathrm{~mm}$. Grinding of the specimens was carried out on wetted silicon carbide papers up to grit size of 1200 followed by fine polishing with diamond, particle size from 6 to $1 \mu \mathrm{m}$, on a nylon cloth, rinsing with water and ethyl alcohol. For best results, 
the polished surface must be mirror-like, i.e., free from any residual layer. After that, the specimens were etched with an etchant composed of $0.5 \%$ nitric acid concentrates, and distilled water. The specimens were then rinsed in anhydrous ethyl alcohol and dried in a blast of dried air. The microstructure of the specimens was analyzed by an optical microscope (OM) (model ZEISS, Germany). Six OM micrographs were taken for each sample from the observed area at low magnification of 100x. The average size of the $\alpha$-Al grains was measured by image analyzer AxioVision SE64 Rel. 4.9 software. All $\alpha$-Al grains existed in one picture taken from the observed area were measured.

Energy dispersion spectrum (EDS) (model INCA PENTAFET X3, England) affiliated to the scanning electron microscope (SEM) (model JSM-5410, Japan) was performed to reveal the concentration of alloying elements in selected areas of the microstructure. Phase constituents of samples were analyzed by X-ray diffraction (XRD) (model LabX XRD-6000, Japan) using $\mathrm{Cu} k \alpha$ radiation in step scan of $2 \theta$ from $20^{\circ}$ to $90^{\circ}$ with an increment of $0.02^{\circ}$ and a scanning speed of $4 \% \mathrm{~min}$.

\subsection{Tensile Test and Fractography Investigation}

Tensile tests were performed using LFM-L-20KN Computer controlled and digital display electromechanical universal testing machine (model LFM-L-20KN (benchtop), Switzerland) with a strain rate of $0.5 \mathrm{~mm} / \mathrm{min}$. The dimensions of a cylindrical tensile specimen are shown in figure 4 according to ASTM E8M. All tensile specimens were cut from the same position. SEM was used to characterize their fracture surfaces.

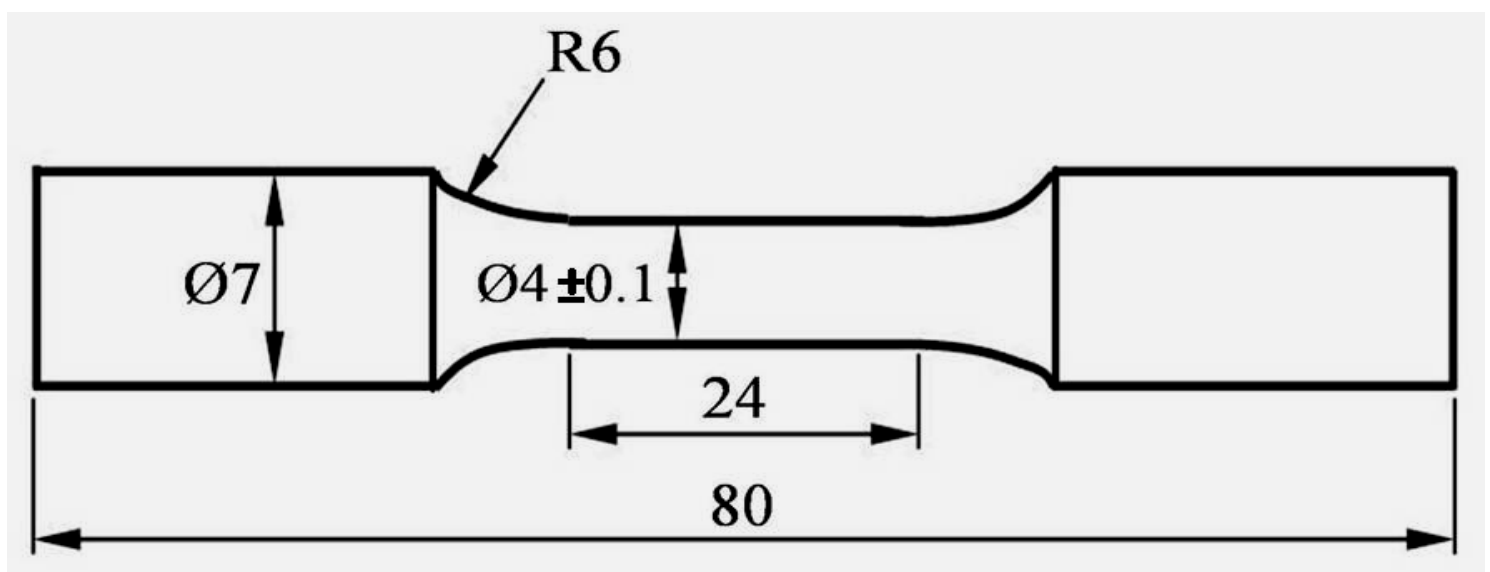

Fig. 4: Dimensions of the tensile specimens $(\mathrm{mm})$.

\section{RESULTS AND DiSCUSSION}

XRD was conducted to ascertain phase constituents of the investigated A356 alloy. XRD results reveal that the constituents of the obtained microstructures are $\alpha$ (Al) phase, $(\mathrm{Si})$ particles and $\left(\mathrm{Mg}_{2} \mathrm{Si}\right)$ intermetallic particles, as shown in figure 5 . 


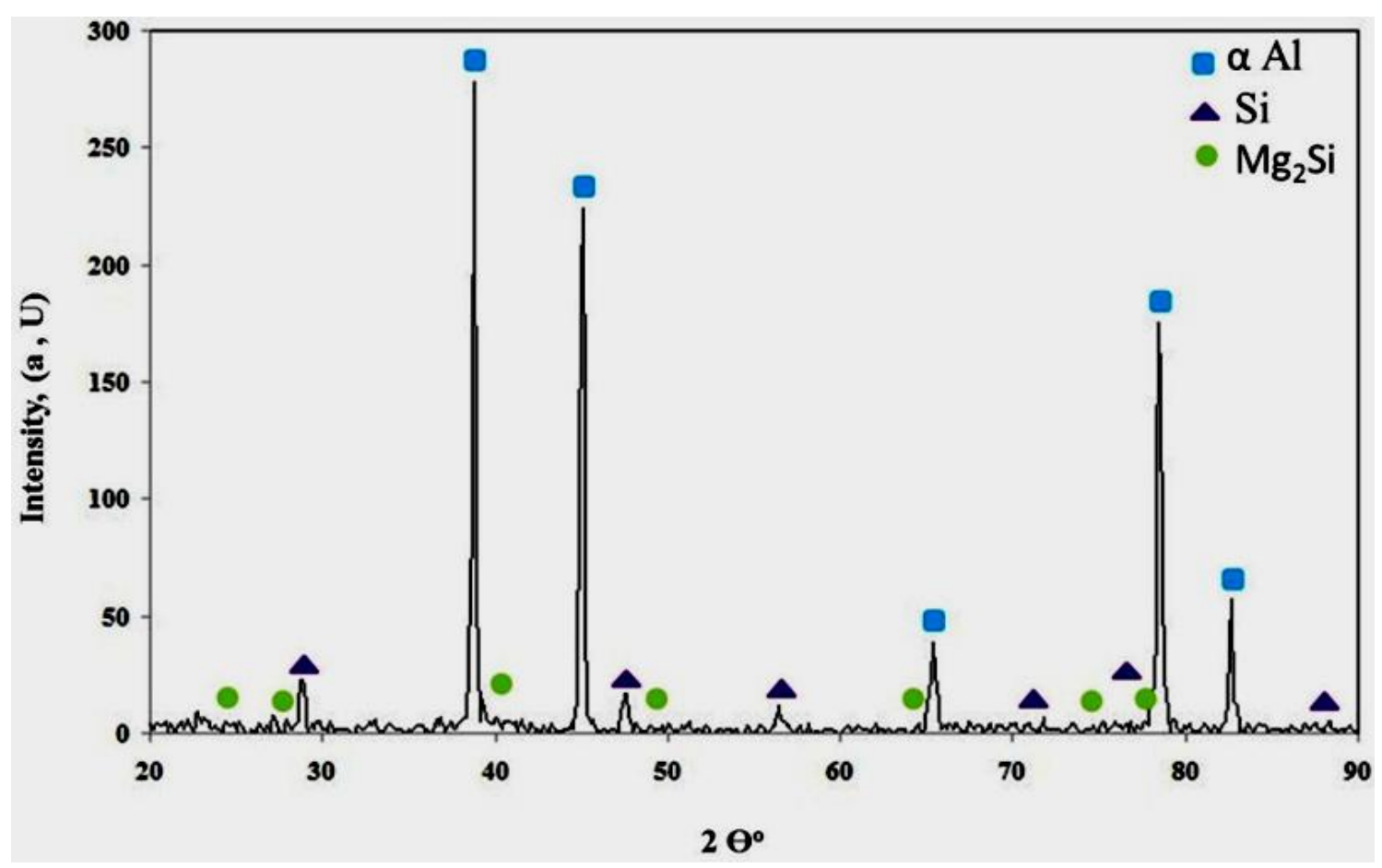

Fig. 5: XRD of the investigated A356 alloy.

Figures 6 and 7 shows the semisolid microstructures and the variation of the average size of primary $\alpha(\mathrm{Al})$ of the investigated A356 alloy without and with the semisolid at different pouring temperatures, respectively. Without semisolid, the microstructure of A356 alloy show a coarse dendritic morphology of primary $\alpha(\mathrm{Al})$ phase as shown in figure 6a with an average size of about $287.5 \mu \mathrm{m}$ (figure 7). The microstructure of A356 alloy with the application of semisolid at $625^{\circ} \mathrm{C}$ was observed to consist of $\alpha(\mathrm{Al})$ phase still having dendritic structure with grain boundaries and few globular grains, as shown in figure $6 \mathrm{~b}$ but their average size was reduced to about $107 \mu \mathrm{m}$, as shown in figure 7 . As the pouring temperature increased to $640^{\circ} \mathrm{C}$, the grain boundaries were also visible and most of the $\alpha(\mathrm{Al})$ phase became globular, as shown in figure $6 \mathrm{c}$, and their average size was reduced significantly to $73 \mu \mathrm{m}$, as shown in figure 7 . When the pouring temperature reached $680^{\circ} \mathrm{C}$, the $\alpha(\mathrm{Al})$ phases became globular, as shown in figure $6 \mathrm{~d}$, and their average size is increased to $84 \mu \mathrm{m}$, as shown in figure 7 . When the pouring temperature was increased to $700^{\circ} \mathrm{C}$, the morphology $\alpha$ the $(\mathrm{Al})$ phase exhibited only few globular grains, as shown in figure 6e and their average size is increased to $189 \mu \mathrm{m}$ as shown in figure 7 . Thus, the modification of the investigated alloy was achieved with the application of semisolid conditions at the optimum pouring temperature of $640^{\circ} \mathrm{C}$, which can be explained on the ground that the inclined plate, which acts as a source of nucleation sites, generates crystalline nuclei in the melt during its flow along the slope $[16,17]$. Crystal separation theory is responsible for the formation of nondendritic morphology in as-cast CS microstructures. The mechanism of necking and detachment of crystals from mold walls which is known as separation theory. According to this theory, granular crystals nucleate and grow on the cooling slope wall and are washed away from the wall by fluid motion. It is fluid alloy into the heated mold, and subsequently becomes granular in the mold resulting in a fine globular microstructure. However, the $\alpha$ phase remains dendritic at the pouring temperature of $625^{\circ} \mathrm{C}$ which is closer to the liquidus temperature $\left(624^{\circ} \mathrm{C}\right)$ of the investigated alloy, due 
to the fact the metal has reached a more viscous state before hitting the cooling plate. Therefore, the detachment of the crystal nuclei from the cooling slope is more difficult. On the other hand, the $\alpha$ phase exhibited growth again by increasing the pouring temperature up to $700^{\circ} \mathrm{C}$ due to the low number of crystal nuclei available at this high temperature, as well as their thermal instability due to overheating.

Figure 8 shows the SEM images of the investigated A356 aluminum alloy in both liquid and semisolid at optimum pouring temperature of $640^{\circ} \mathrm{C}$. The SEM micrographs, EDS line scan and EDS elemental mapping of $\mathrm{Al}, \mathrm{Si}, \mathrm{Mg} 2 \mathrm{Si}$ for the investigated A356 aluminum alloy without and with semisolid at optimum pouring temperature of $640^{\circ} \mathrm{C}$ are shown in figures 9 and 10, respectively. It can be seen that the coarser $\alpha$ (Al) dendritic phase is formed with a non-uniform distribution without semisolid as shown in figures $8 \mathrm{a}$ and 9. With the application of the semisolid, the morphology of $\alpha$ (Al) phase changes from coarse dendritic structure to fine globular shape structure with a homogeneous distribution observed (figures $8 b$ and 10).
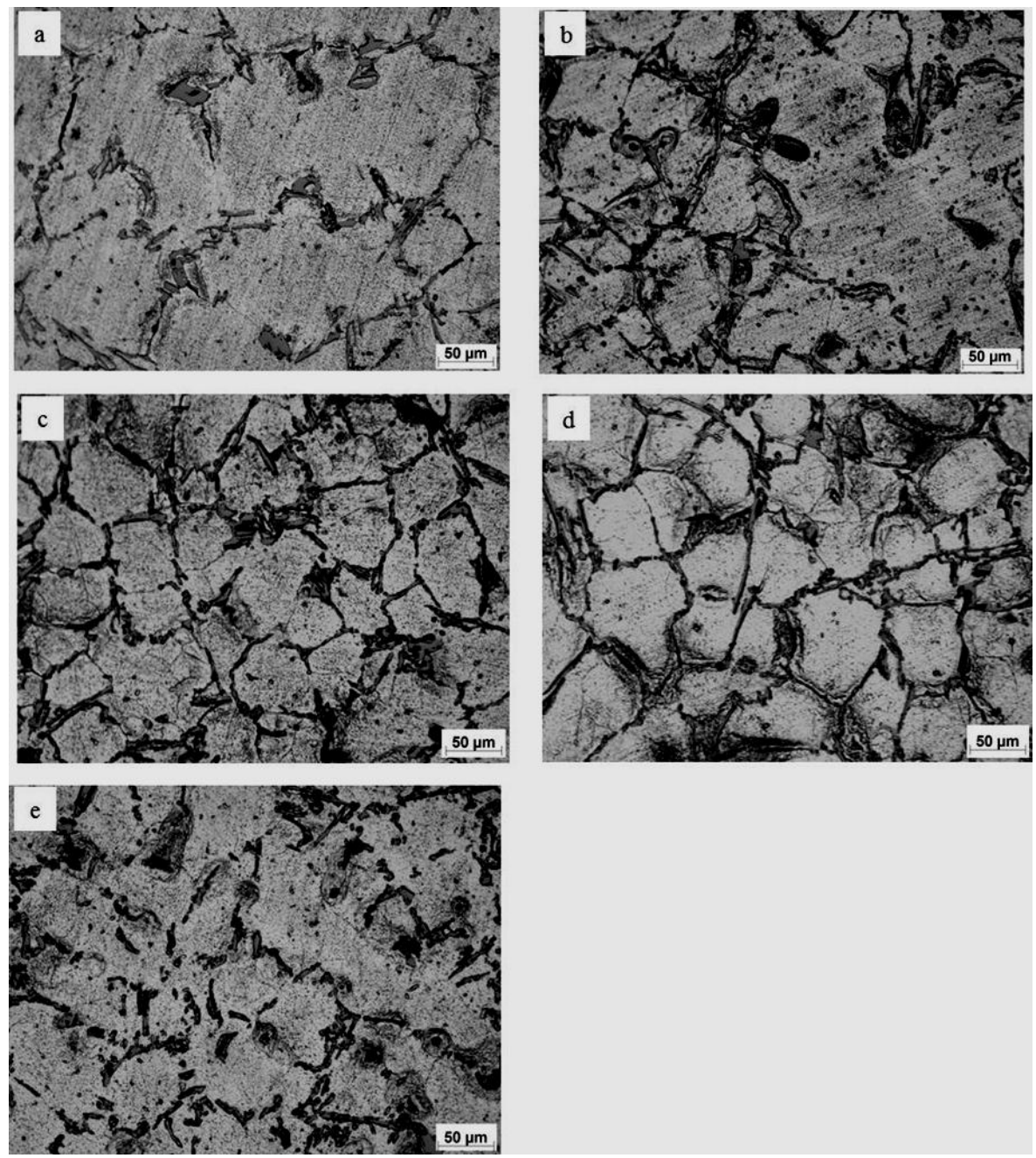

Fig. 6: OM micrographs of the investigated A356 alloy (a)Without semisolid and with semisolid at different pouring temperatures of (b) $625^{\circ} \mathrm{C}$, (c) $640^{\circ} \mathrm{C}$, (d) $680^{\circ} \mathrm{C}$ and (e) $700^{\circ} \mathrm{C}$. 


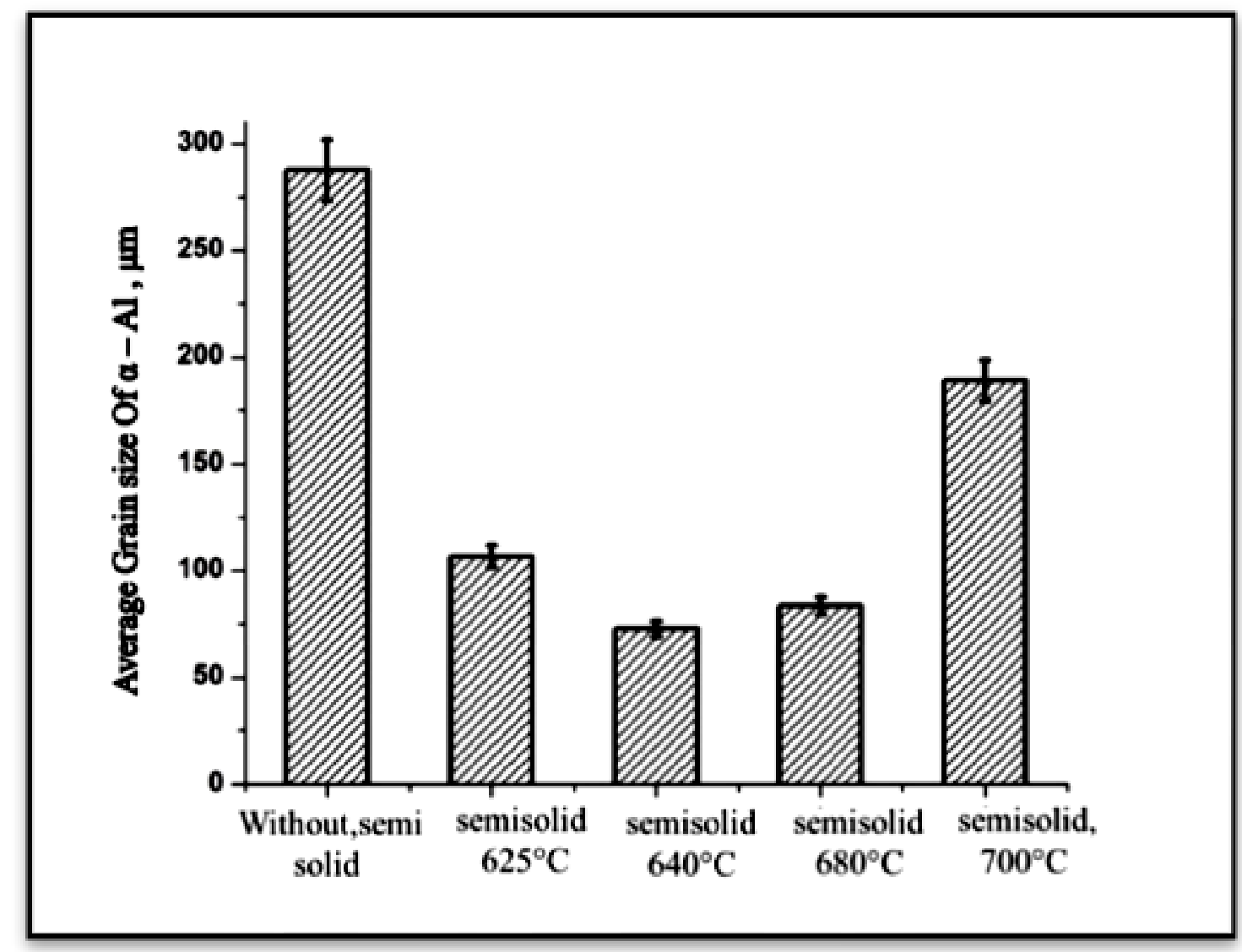

Fig. 7: Variation of the average size of primary $\alpha$ (Al) of the investigated A356 alloy without and with the semisolid at different pouring temperatures.
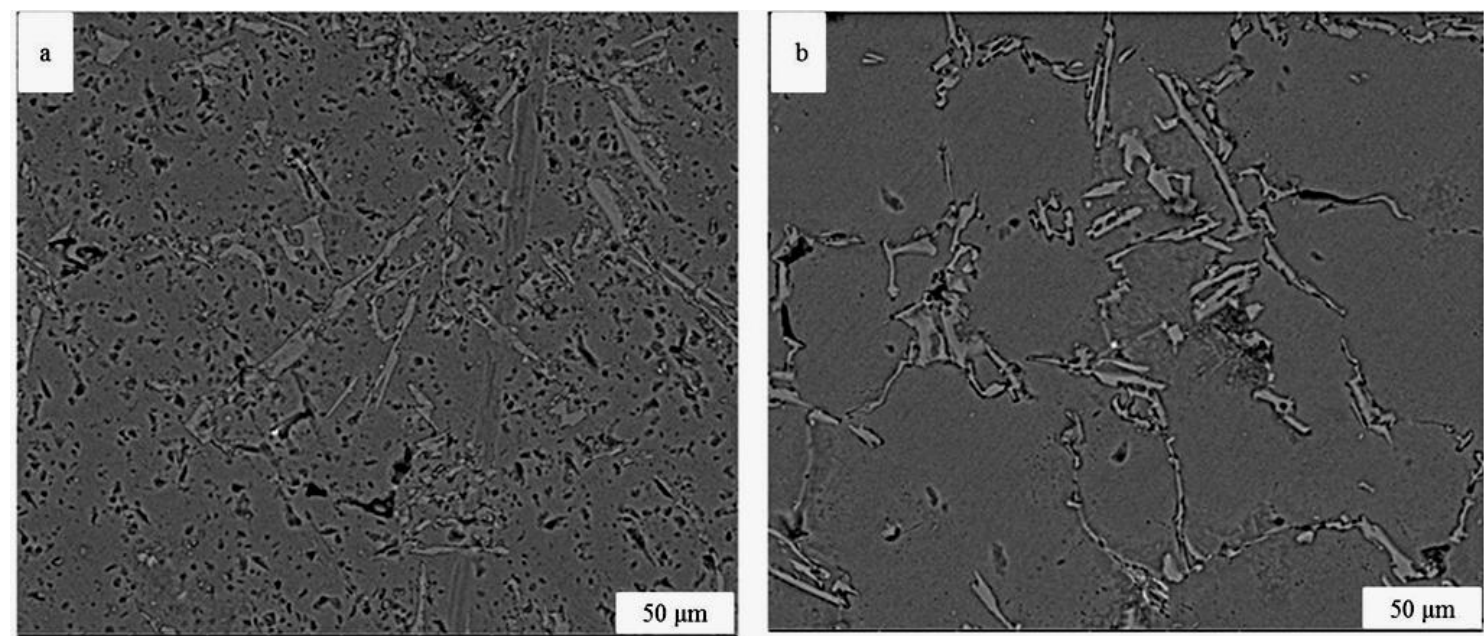

Fig. 8: SEM micrograph of the investigated A356 alloy (a) without and (b) with semisolid at optimum pouring temperature of $640^{\circ} \mathrm{C}$. 

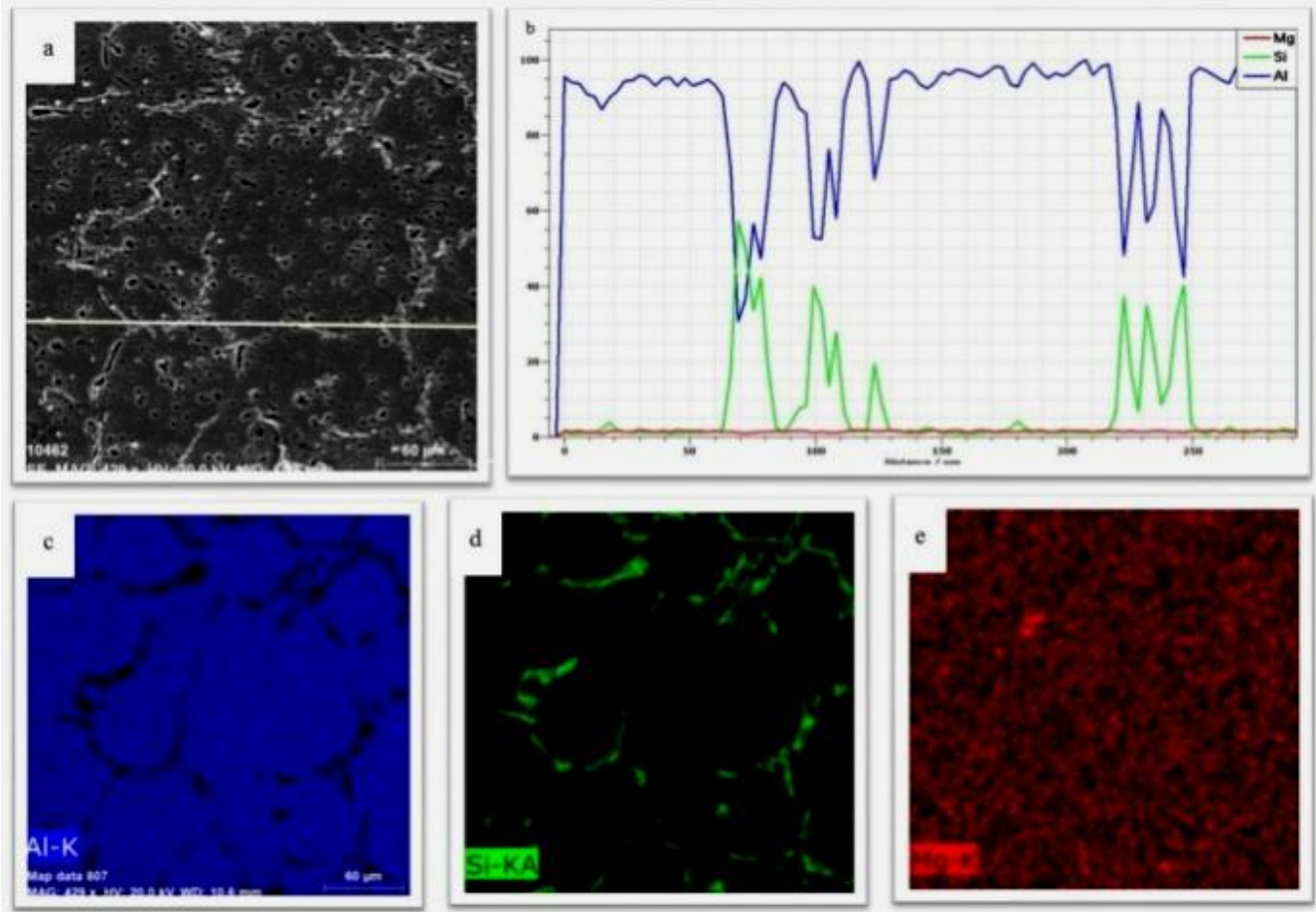

Fig. 9: (a) SEM micrograph with (b) line scan and elemental mapping of (c) Al, (d) $\mathrm{Si}$ and (e) $\mathrm{Mg}_{2} \mathrm{Si}$ of the investigated $\mathrm{A356}$ alloy processed without semisolid.
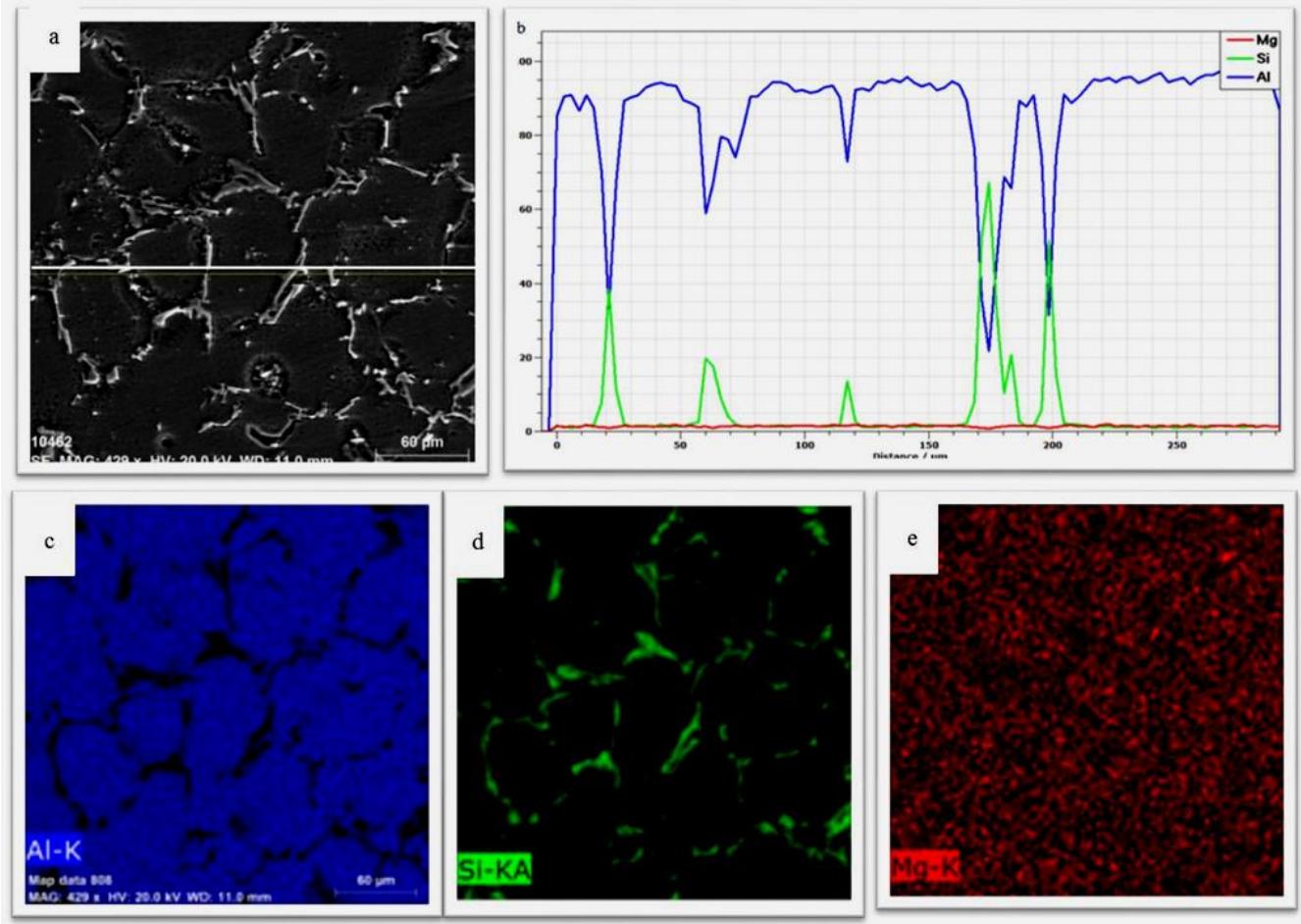

Fig. 10: (a) SEM micrograph with (b) line scan and elemental mapping of (c) Al, (d) $\mathrm{Si}$ and (e) $\mathrm{Mg}_{2} \mathrm{Si}$ of the investigated $\mathrm{A356}$ alloy processed with semisolid at optimum pouring temperature of $640^{\circ} \mathrm{C}$. 
Figures 11 and 12 show the effect of semisolid casting on the ultimate tensile strength (UTS) and the elongation of the investigated A356 alloy at the different pouring temperatures. It is shown that the ultimate tensile strength and the elongation of the investigated alloy with semisolid casting are higher than that of the investigated alloy without semisolid casting, implying that semisolid casting of the investigated A356 alloy can improve the ultimate tensile strength and the elongation of this alloy. The ultimate tensile strength and the elongation of the investigated alloy significantly increase from $102 \mathrm{MPa}$ and $1.175 \%$ without semisolid casting to $113 \mathrm{MPa}$ and $3.6 \%$ with semisolid casting at the optimum pouring temperature of $640^{\circ} \mathrm{C}$, respectively then gradually decrease with further increase of the pouring temperature. It is well known that the fine microstructure is usually beneficial to tensile properties of engineering alloys. According to Griffith's theory [19], the fracture stress of a material increases with decreasing particle size, inversely proportion to the square root of the particle size. In the present work, the coarse dendritic primary $\alpha-\mathrm{Al}$ in the investigated A356 alloy without semisolid casting will give a detrimental effect on the tensile properties because of the sharp tips of the primary $\alpha$-Al that act as stress and crack initiation sites under applied stress. These cracks can easily propagate along with the interface between the $\alpha$ Al phases. Therefore, it can be inferred that the improvement of the tensile properties for the investigated alloy modified by semisolid casting at the optimum pouring temperature of $640^{\circ} \mathrm{C}$, is related to the modification and refinement of the primary $\alpha-\mathrm{Al}$. Figure 13 shows the SEM micrographs of the fracture surfaces of the investigated A356 alloy without semisolid casting and with semisolid casting at the optimum pouring temperature of $640^{\circ} \mathrm{C}$. The SEM micrographs of the fracture surface of the investigated A356 alloy without semisolid casting shows few dimples and non-uniform distribution, indicating a dimpled quasi-cleavage fracture mechanism, as shown in figure 13a. With semisolid casting at the optimum pouring temperature of $640^{\circ} \mathrm{C}$, most of the primary $\alpha$ $\mathrm{Al}$ phases are modified and refined as well as the deformation zone on the fractography of the alloy is enlarged considerably and the dimples are deep and distributed uniformly as shown in figure $13 \mathrm{~b}$, which increases its tensile strength and elongation. The fracture mode becomes ductile fracture. As a result, the fracture generated mostly by dimple rupture with cracked eutectic silicon particles, and exhibited an intergranular fracture mode, leading to the optimum mechanical properties [20]. 


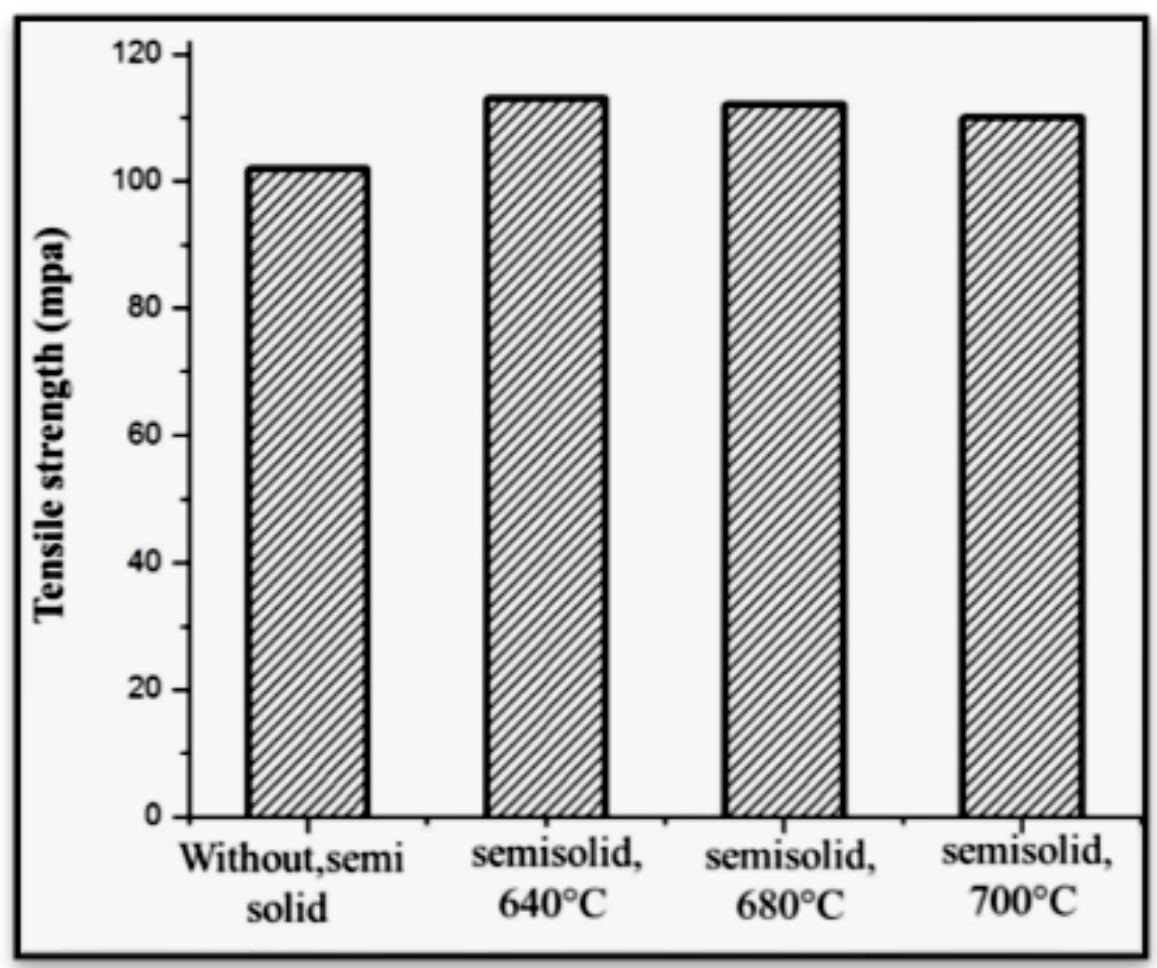

Fig. 11: The ultimate tensile strength of the investigated A356 alloy without and with semisolid at the different pouring temperatures.

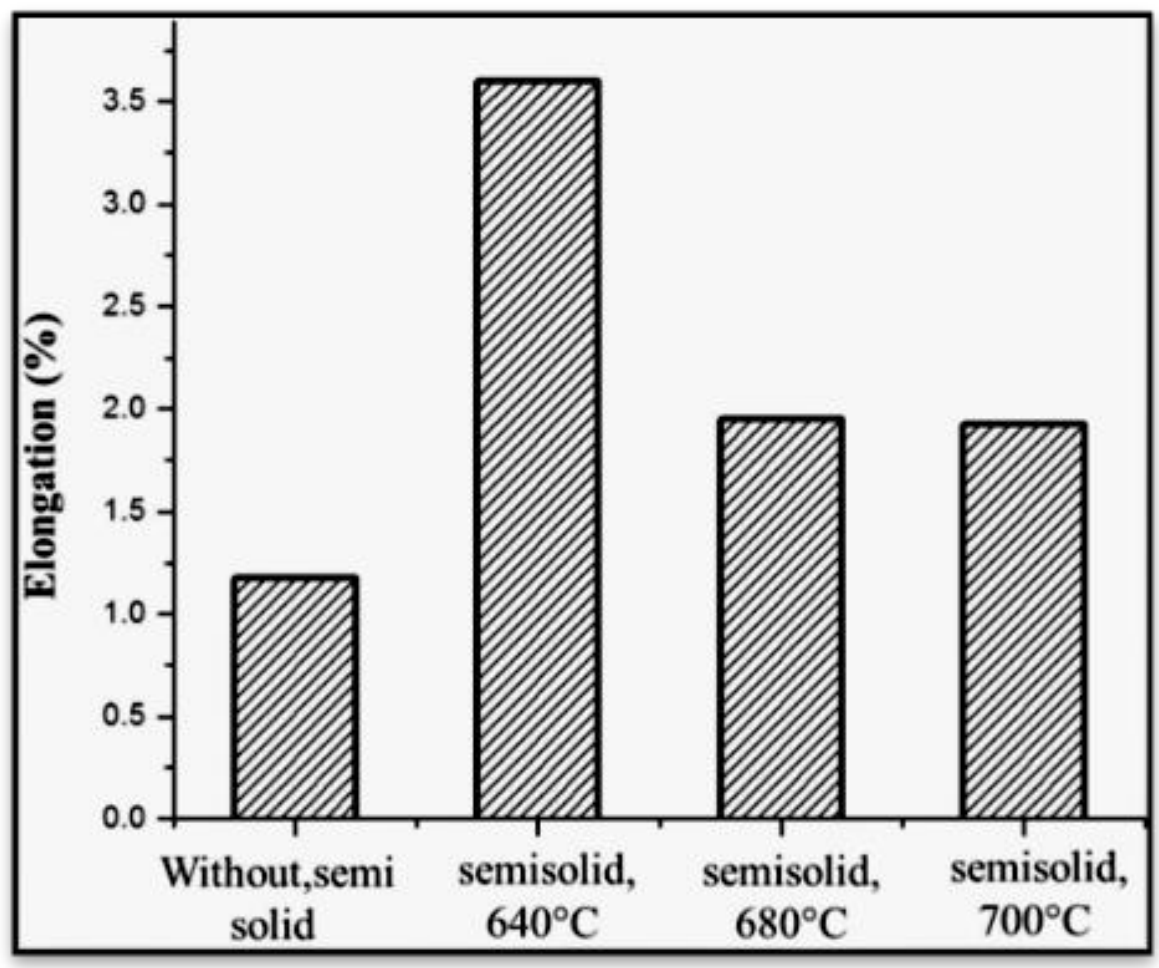

Fig. 12: The elongation of the investigated A356 without and with semisolid at the different pouring temperatures. 


TIMS Bulletin $\quad$ Volume 109 August 2021
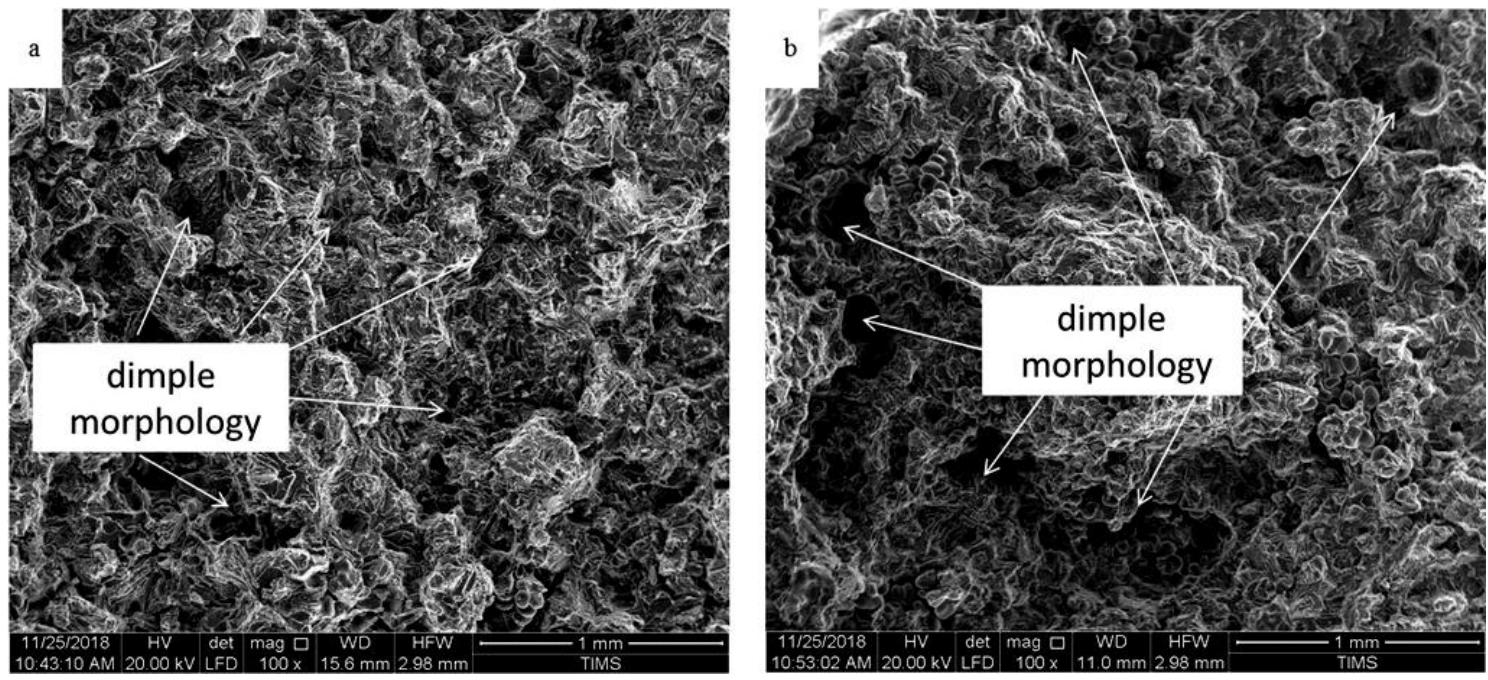

Fig. 13: SEM micrographs of the fracture surfaces of the investigated A356 alloy (a) without semisolid casting and (b) with semisolid casting at the optimum pouring temperature of $640^{\circ} \mathrm{C}$.

\section{Conclusions}

- Semisolid casting is suitable method for producing a globular casting structure of A356 alloy.

- The application of semisolid casting at the optimum pouring temperature of $640^{\circ}$ leads to a fine globular structure of the primary $\alpha$-Al phases as compared to without application of semisolid.

- The pouring temperature below the optimum pouring temperature of $640^{\circ} \mathrm{C}$ leads to a decrease in the nucleus due to the high viscosity of the semisolid slurry.

- Increasing the pouring temperature above the optimum pouring temperature of $640^{\circ} \mathrm{C}$ leads to the remelting of the nucleus due to the overheat of the melt.

- The tensile strength and the elongation of the investigated castings were improved with applying semisolid casting at the optimum pouring temperature of $640^{\circ} \mathrm{C}$.

- The fracture mode of the investigated alloy transfers from a dimpled quasi-cleavage fracture without applied semisolid to ductile fracture with applied semisolid at the optimum pouring temperature of $640^{\circ} \mathrm{C}$.

\section{ACKNOWLEDGMENT}

The authors would like to appreciate the technician support from the Central Metallurgical Research and Development Institute (CMRDI), Ministry of Scientific Research, Egypt.

\section{REFERENCES}

[1] Kapranos, P.; Kirkwood, D. H. and Sellars, C. M.: "3 ${ }^{\text {rd }}$ Int. conf. on semisolid processing of alloys and composites", Tokyo - Japan, pp. 117-126, (1994).

[2] Fan, Z.:"Semisolid metal processing", International materials reviews, 47, pp. 49-85, (2002). 
[3] Atkinson, V. H.: "Modeling the semisolid processing of metallic alloys", Progress in materials science, 50, pp. 341-412, (2005).

[4] Taghavi, F. and Ghassemi, A.: "Study on the effects of the length and angle of inclined plate on the thixotropic microstructure of A356 aluminum alloy", Materials \& Design, 30, pp. 1762-1767, (2009).

[5] Spencer, D. B.; Mehrabian, R. and Flemings, M. C.: "Rheological behavior of Sn-15 pct $\mathrm{Pb}$ in the crystallization range", Metallurgical Transactions, 3, pp. 1925-1932, (1972).

[6] Flemings, M. C.: "Behavior of metal alloys in the semisolid state", Metallurgical transactions, A 22A, pp. 957-981, (1991).

[7] Czerwinski, F.: "The basics of modern semi-solid metal processing", JOM, 58.6, pp. 17-20, (2006).

[8] Kirkwood, D. H.: "Semisolid metal processing", International materials reviews, 39, pp. 173-189, (1994).

[9] Atkinson, H. V.: "Semi-Solid Processing of Metallic Materials", Material Science and Technology, 26, pp. 1401-1413, (2010).

[10] Miller, W. S.; Zhuang, L.; Bottema, J.; Wittebrood, A. J.; Smet, P. D.; Haszler, A. and Vieregge, A.: "Recent development in aluminum alloys for the automotive industry", Materials Science and Engineering, A 280, pp. 37-49, (2000).

[11] Liu, D.; Atkinson, H. V.; Kapranos, P.; Jirattiticharoean, W. and Jones, H.: "Microstructural evolution and tensile mechanical properties of thixoformed high performance aluminum alloys", Materials Science and Engineering, A 361, pp. 213224, (2003).

[12] Paes, M. and Zoqui, E. J.: "Semi-solid behavior of new Al-Si-Mg alloys for thixoforming", Materials Science and Engineering, A 406, pp. 63-73, (2005).

[13] Salleh, M. S.; Omar, M. Z.; Syarif, J. and Mohammed: "An overview of semisolid processing of aluminum alloys" ISRN Materials Science, 2013, pp. 1-9, (2013).

[14] Moussa, M. E.; El-hadad, S. and Khalifa, W.: "Influence of chemical modification by $\mathrm{Y}_{2} \mathrm{O}_{3}$ on eutectic $\mathrm{Si}$ characteristics and tensile properties of A356 alloy", Transactions of Nonferrous Metals Society of China, 29, pp. 1365-1374, (2019).

[15] Haga, T.; Tkahashi, K.; Ikawaand, M. and Watari, H.: "Twin roll casting of aluminum alloy strips" Journal of Materials Processing Technology, 152-153, pp. 42-47, (2004).

[16] Robert, M. H.; Zoqui, E. J.; Tanabe, F. and Motegi, T.: "Producing thixotropic semisolid A356 alloy: microstructure formation $\mathrm{x}$ forming behavior", Journal of Achievements in Materials and Manufacturing Engineering, 20, pp. 19-26, (2007).

[17] Legoretta, E. C.; Atkinson, H. V. and Jones, H.: "Cooling slope casting to obtain thixotropic feedstock II: observations with A356 alloy", Journal of Materials Science, 43, pp. 5456-5469, (2008).

[18] Kumar, S. D.; Mandal, A. and Chakraborty, M.: "Cooling Slope Casting Process of Semi-solid Aluminum Alloys: A Review", International Journal of Engineering Research and Technology, 3, pp. 269-283, (2014).

[19] Cong, M.; Li, Z.; Liu, J. and Li, S.: "Effect of Sr on microstructure, tensile properties and wear behavior of as-cast Mg-6Zn-4Si alloy", Materials \& Design, 53, pp. 430434, (2014).

[20] Ceschini, L.; Jarfors A. and Morri, A.: "High temperature tensile behavior of the A354 aluminum alloy", Materials Science Forum, 794-796, pp. 443-448, (2014). 